\title{
Comment on "Preliminary outcome of microwave ablation of hepatocellular carcinoma: breaking the 3-cm barrier?"
}

\section{Paola Tombesi, Francesca Di Vece, Francesca Ermili, Sergio Sartori}

Section of Interventional Ultrasound, St. Anna Hospital, 44100 Ferrara, Italy.

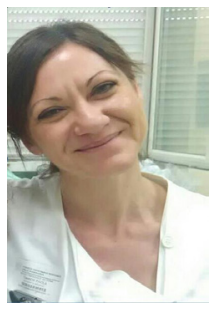

\begin{abstract}
Dr. Paola Tombesi was born on April 27, 1976, and graduated cum laude in 2001. She is specialist in Internal Medicine and is dealing with interventional ultrasonography from 2003. She is working in the Section of Interventional Ultrasound, St. Anna Hospital, Ferrara, Italy, from 2006, and is author of 61 scientific papers.
\end{abstract}

Corresponding Author:

Dr. Paola Tombesi, Section of Interventional Ultrasound, St. Anna Hospital, 44100 Ferrara, Italy. E-mail: p.tombesi@ospfe.it

Received: 13-07-2016; Accepted: 20-07-2016

Thamtorawat S, Hicks R, Yu J, Siripongsakun S, Lin WC, Raman S, McWilliams JP, Douek M, Bahrami S, Lu DSK. Preliminary outcome of Microwave ablation of hepatocellular carcinoma: breaking the 3-cm barrier? J Vasc Interv Radiol 2016;27:623-30.

Nowadays, surgical resection represents the gold standard for the treatment of hepatocellular carcinoma (HCC) in eligible patients, and liver transplantation is considered the best option for selected patients with HCC. However, in the last years the role of thermal ablation therapies is becoming more and more relevant. Their effectiveness and safety have widely been proven, and they play a key role in the treatment of HCC patients who are not eligible or poor candidates for surgery, or who refuse surgery. ${ }^{[1-4]}$ Moreover, they can also be used as a bridge to liver transplantation.

In the Barcelona Clinic Liver Cancer (BCLC) guidelines for treatment of HCC, tumors up to $3 \mathrm{~cm}$ in diameter are considered eligible for radiofrequency ablation (RFA) with curative intent in non-surgical candidates. ${ }^{[5]}$ Moreover, recent studies showed that RFA of very early HCC is as effective as surgical resection in terms of overall survival and recurrencefree survival rates. ${ }^{[6,7]}$ On the basis of these reports and their own experience, most skilled interventional oncologists and radiologists are advocating an update of the current guidelines, as it is time to consider RFA at least equivalent to surgical resection in the treatment of HCC up to $2 \mathrm{~cm}$, in particular when the liver tumor is centrally located.

RFA represents the "historical", best established and

\begin{tabular}{|l|c|}
\hline \multicolumn{3}{|c|}{ Access this article online } \\
\hline \multirow{2}{*}{ Website: } & Quick Response Code \\
www.hrjournal.net/ & \\
\hline &
\end{tabular}

experienced thermal ablation technique, but its efficacy is well known to decrease in presence of tumors larger than 2-3 cm. Last generation microwave ablation (MWA) systems offer some advantages compared with RFA, such as greater intratumoral temperature, deeper penetration of energy, propagation across the poorly conductive tissues, less sensitivity to the heat-sink effect, and larger ablation volume. These peculiarities could enable to treat larger tumors than RFA with adequate safety margin. So to date the question is: is it time to break the $3-\mathrm{cm}$ barrier for thermal ablation?

To the best of our knowledge, no previous studies compared the efficacy of MWA in nodules up to $5 \mathrm{~cm}$ with respect to nodules up to $3 \mathrm{~cm}$. Thamtorawat et al. ${ }^{[8]}$ recently published an interesting retrospective study including 129 patients with 173 HCCs up to $5 \mathrm{~cm}$ treated with MWA: 118 nodules were $\leq 3 \mathrm{~cm}$ in size, whereas 55 nodules were from 3.1 to $5 \mathrm{~cm}$ in size. The reported overall technical success rate of MWA was 96.5\%. Local tumor progression occurred in 20/173 tumors (11.6\%), and recurrences were successfully retreated by additional thermal ablation session. The mean follow-up period was $11.8 \pm 9.8$ months. The 1 -year and 2 -year overall survival rates for nodules $\leq 3 \mathrm{~cm}$ and for nodules from 3.1 to $5 \mathrm{~cm}$ were $91.3 \%$ and $81.7 \%$, respectively. Eighteen patients out of 129 (13.9\%) were bridged to liver transplantation.

Interestingly, there was no statistically significant difference in local progression rates between the two groups of HCC, with a 2-year local tumor control of $83.9 \%$ and $82.1 \%$, respectively.

This is an open access article distributed under the terms of the Creative Commons Attribution-NonCommercial-ShareAlike 3.0 License, which allows others to remix, tweak, and build upon the work non-commercially, as long as the author is credited and the new creations are licensed under the identical terms.

For reprints contact: service@oaepublish.com

How to cite this article: Tombesi P, Di Vece F, Ermili F, Sartori $\mathrm{S}$. Comment on "Preliminary outcome of microwave ablation of hepatocellular carcinoma: breaking the $3-\mathrm{cm}$ barrier?" Hepatoma Res 2016;2:237-8. 
As reported by the authors, the study has some limitations. First, it is a retrospective non-randomized study. Second, all the treatments were performed by using MWA. Therefore, a comparison with other thermal techniques is not possible. Finally, long-term outcome would also require longer followup times. However, as stated by the authors, this study was intended to be a pilot report on the treatment of larger HCC by using MWA.

Surgical resection and RFA can actually achieve the same good results in the treatment of very-early HCC $(\leq 2$ $\mathrm{cm})$. Surgical resection remains the gold standard for the treatment of early $(<3 \mathrm{~cm}) \mathrm{HCC}$, although RFA represents an effective alternative in patients who are not eligible for surgery. Based on the BCLC guidelines, single nodules from 3 to $5 \mathrm{~cm}$ are classified as intermediate $\mathrm{HCC}$, and transarterial chemoembolisation (TACE) is recommended as the best treatment option. ${ }^{[5]}$ Nevertheless, most experts consider surgery the very best option for the treatment of resectable large nodules with curative intent. However, most patients with intermediate HCC are not eligible for surgery because of inadequate liver function, anatomic limitations, multifocal disease, or medical comorbidities. This group of patients can benefit from TACE, or combined treatments including RFA plus TACE. RFA alone is frequently unable to obtain an adequate safety margin in nodules $>3 \mathrm{~cm}$, particularly when the tumor is strictly close to large vessels, because thermal energy is partially shunted away by the cooler blood (the socalled heat-sink effect). ${ }^{[9,10]}$ Moreover, the treatment of large nodules require multiple overlapping insertions of the needle electrode, and it is known that the insertions following the first or second ones can be inaccurate owing to the steam generated during the procedure. ${ }^{[1]}$ As a consequence of these limitations, at present the use of RFA alone with curative intent is limited to nodules up to $3 \mathrm{~cm}$.

Several studies demonstrated that last generation MWA systems enable to achieve larger ablation volumes than RFA, with comparable safety and survival rates. ${ }^{[12-16]} \mathrm{A}$ randomized prospective comparison of MWA and RFA in the treatment of HCC did not demonstrate any difference in the rates of residual or untreated disease, ${ }^{[17]}$ and the capability of MWA to produce larger coagulation areas could result particularly useful in the treatment of tumors $\geq 3 \mathrm{~cm}$. Reported mortality and major complication rates using the most recent MWA devices are similar to RFA. ${ }^{[18]}$ Complication rates reported by Thamtorawat et al. ${ }^{[8]}$ agree with the data reported by other authors, despite the larger size of the treated nodules. Moreover, although MWA appears less feasible than RFA in the treatment of high-risk located and subcapsular nodules, no difference in local tumor progression rate was found for subcapsular nodules in the study of Thamtorawat et al..$^{[8]}$

In conclusion, in our opinion this article could be considered the starting point for breaking the $3-\mathrm{cm}$ barrier in the treatment of non surgical HCC. Our preliminary experience in the treatment of large nodules supports the efficacy of MWA for HCC up to $5 \mathrm{~cm}$ (unpublished data), and we hopefully expect further studies with longer follow-up aimed at extending the dimensional barrier of thermal ablation with curative intent.

\section{Financial support and sponsorship}

Nil.

\section{Conflicts of interest}

There are no conflicts of interest.

\section{REFERENCES}

1. Bruix J, Sherman M; Practice Guidelines Committee, American Association for the Study of Liver Disease. Management of hepatocellular carcinoma. Hepatology 2005;42:1208-36.

2. Yao FY, Bass NM, Nikolai B, Davern TJ, Kerlan R, Wu V, Ascher NL, Roberts JP. Liver transplantation for hepatocellular carcinoma: analysis of survival according to the intention-to-treat principle and dropout from the waiting list. Liver Transplant 2002;8:873-83.

3. Gervais DA, Goldberg SN, Brown DB, Soulen MC, Millward SF, Rajan DK. Society of Interventional Radiology position statement on percutaneous radiofrequency ablation for the treatment of liver tumors. J Vasc Interv Radiol 2009;20:S342-7.

4. McCarley JR, Soulen MC. Percutaneous ablation of hepatic tumors. Semin Intervent Radiol 2010;27:255-60.

5. Bruix J, Sherman N; American Association for the Study of Liver Diseases. Management of hepatocellular carcinoma: an update. Hepatology 2011;53:1020-2.

6. Peng ZW, Lin XJ, Zhang YJ, Liang HH, Guo RP, Shi M, Chen MS. Radiofrequency ablation versus hepatic resection for the treatment of hepatocellular carcinoma $2 \mathrm{~cm}$ or smaller: a retrospective comparative study. Radiology 2012;262:1022-33.

7. Tombesi P, Di Vece F, Sartori S. Resection vs. thermal ablation of small hepatocellular carcinoma: what's the first choice? World J Radiol 2013;5:1-4.

8. Thamtorawat S, Hicks R, Yu J, Siripongsakun S, Lin WC, Raman S, McWilliams JP, Douek M, Bahrami S, Lu DSK. Preliminary outcome of microwave ablation of hepatocellular carcinoma: breaking the 3-cm barrier? J Vasc Interv Radiol 2016;27:623-30.

9. Mulier S, Jamart J, Ruers T, Marchal G, Michel L. Local recurrence after hepatic radiofrequency coagulation: multivariate meta-analysis and review of contributing factors. Ann Surg 2005;242:158-71.

10. Lu DS, Raman SS, Limanond P, Aziz D, Economou J, Busuttil R, Sayre J. Influence of large peritumoral vessels on outcome of radiofrequency ablation of liver tumors. J Vasc Interv Radiol 2003;14:1267-74.

11. Di Vece F, Tombesi P, Ermili F, Maraldi C, Sartori S. Coagulation areas produced by cool-tip radiofrequency ablation and microwave ablation using a device to decrease back-heating effects: a prospective pilo study. Cardiovasc Intervent Radiol 2014;37:723-9.

12. Lu MD, Xu HX, Yin XY, Chen JW, Kuang M, Xu ZF, Liu GJ, Zheng YL. Percutaneous microwave and radiofrequency ablation for hepatocellular carcinoma: a retrospective comparative study. $J$ Gastroenterol 2005;40:1054-60.

13. Simon CJ, Dupuy DE, Mayo-Smith WW. Microwave ablation principles and applications. Radiographics 2005;25 Suppl 1:S69-83.

14. Boutros C, Somasundar P, Garrean S, Saied A, Espat NJ. Microwave coagulation therapy for hepatic tumors: review of the literature and critical analysis. Surg Oncol 2010;19:e22-32.

15. Lubner MG, Brace CL, Ziemlewicz TJ, Hinshaw JL, Lee FT Jr. Microwave ablation of hepatic malignancy. Semin Intervent Radiol 2013;30:56-66.

16. Qian GJ, Wang N, Shen YH, Zhao JQ, Kuang M, Liu GJ, Wu MC. Efficacy of microwave versus radiofrequency ablation for treatment of small hepatocellular carcinoma: experimental and clinical studies. Eur Radiol 2012;22:1983-90.

17. Shibata T, Iimuro Y, Yamamoto Y, Ametani F, Itoh K, Konishi J. Small hepatocllular carcinoma: comparison of radio-frequency ablation and percutaneous microwave coagulation therapy. Radiology 2002;223:331-7

18. Livraghi T, Meloni S, Solbiati L, Zanus G; Collaborative Italian Group using AMICA System. Complications of microwave ablation for liver tumors: results of a multicenter study. Cardiovasc Intervent Radiol 2012;35.868-74. 